\title{
PENGARUH LEVERAGE DAN PROFITABILITAS TERHADAP RETURN SAHAM PADA PT. SEMEN GRESIK SURTICON BUANA PERKASA Tbk. DENPASAR
}

\author{
Viky Ahmad Aditya ${ }^{1}$ \\ I Made Sumartana ${ }^{2}$ \\ ${ }^{1,2}$ Fakultas Ekonomi Universitas Ngurah Rai, Bali, Indonesia \\ 1e-mail : vikiaditya021@gmail.com
}

\begin{abstract}
ABSTRAK
Leverage dan pofitabilitas terhadap return saham pada PT. Semen Gersik Surticon Buana Perkasa Tbk. Denpasar. Teknik analisis data yang digunakan meliputi uji asumsi klasik, analisis regresi linier berganda, uji signifikansi simultan (F-test), dan uji signifikansi parsial (t-test). Berdasarkan hasil analisis data, uji signifikansi simultan (F-test) dapat menunjukkan bahwa leverage dan profitabilitas secara simultan berpengaruh positif dan signifikan terhadap return saham, hasil uji signifikansi parsial (t-test) menunjukkan bahwa leverage secara parsial berpengaruh positif dan signifikan terhadap return saham dan profitabilitas secara parsial berpengaruh positif dan signifikan terhadap return saham.
\end{abstract}

Kata kunci : Leverage, Profitability, Return On Assets (ROA), Stock Return

\begin{abstract}
Based on this, a study was conducted on the effect of leverage and profitability on stock returns at PT. Semen Gersik Surticon Buana Perkasa Tbk. Denpasar. Data analysis techniques used include the classic assumption test, multiple linear regression analysis, simultaneous significance test $(F$-test), and partial significance test ( $t$-test). Based on the results of data analysis, simultaneous significance test ( $F$-test) can show that leverage and profitability simultaneously have a positive and significant effect on stock returns, the results of the partial significance test (t-test) show that leverage partially has a positive and significant effect on stock returns and profitability partially has a positive and significant effect on stock returns.
\end{abstract}

Keywords: Leverage, Profitability, Return On Assets (ROA), Stock Return 


\section{PENDAHULUAN}

Untuk mengoptimalkan return yang diterima investor dapat melakukan serangkaian analisis laporan keuangan perusahaan. Teknik analisis yang umum dipergunakan investor adalah teknik analisis rasio. Analisis rasio dilakukan dengan membandingkan pos - pos tertentu dalam neraca atau laporan labarugi individual atau kombinasi kedua laporan tersebut.

Mengingat tujuan setiap usaha bisnis adalah untuk meraih laba, maka rasio-rasio yang menunjukkan kemampuan perusahaan dalam menghasilakan laba (profitabilitas) akan mencerminkan tingkat efektifitas pengelolaan yang dilakukan oleh manajemen perusahaan. Salah satu rasio profitabilitas yang menarik perhatian investor adalah Return On Assets (ROA). ROA merupakan pengukuran kemampuan perusahaan secara keseluruhan di dalam menghasilkan keuntungan dengan jumlah keseluruhan aktiva yang tersedia di dalam perusahaan. Semakin besar ROA menunjukkan kinerja yang semakin baik, karena tingkat kembalian semakin besar. Dengan meningkatnya kinerja perusahaan, maka Leverage saham perusahaan di pasar modal meningkat dan hal ini berdampak pada peningkatan return saham. Ketertarikan investor pada perusahaan yang menghasilkan ROA tinggi mendorong peningkatan permintaan kepemilikan saham sehingga Leverage saham perusahaan menjadi meningkat. Sedangkan rasio leverage adalah rasio yang digunakan untuk mengukur kemampuan perusahaan dalam memenuhi kewajiban jangka panjangnya.
Rasio leverage yang digunakan untuk mengukur tingkat penggunaan utang terhadap total asset yang dimiliki perusahaan adalah debt ratio. Semakin tinggi debt ratio menunjukkan semakin tinggi modal pinjaman (utang) yang digunakan perusahaan di dalam menghasilkan keuntungan. Dalam kondisi ini beban bunga yang ditanggung perusahaan-perusahaan menjadi semakin tinggi. Kegagalan perusahaan dalam membayar bunga atas utang dapat menyebabkan kesulitan keuangan yang berakhir dengan kebangkrutan perusahaan. Total kewajiban (utang) yang semakin meningkat menunjukkan beban keuangan perusahaan semakin besar sehingga Leverage saham tersebut di pasar modal semakin menurun. Dengan menurunnya Leverage saham, maka return saham perusahaan menurun pula. Dengan demikian penggunaan leverage yang baik bagi perusahaan adalah memperoleh laba dan meningkatkan return untuk pemegang saham. Dalam penggunaan utang pada dasarnya terdapat dua metode perencanaan pengembaliannya yaitu pengembalian jangka pendek dan jangka panjang sebagaimana yang telah disepakati oleh dua belah pihak.

Hal ini menunjukkan bahwa perusahaan memerlukan cara bagaimana memperoleh dana dengan beban tetap. Oleh karena itu, perusahaan membutuhkan leverage keuangan. Perusahaan yang menggunakan dana dengan beban tetap disebut menghasilkan leverage yang menguntungkan (favorable) apabila 
pendapatan yang diterima lebih besar daripada beban tetap. Sedangkan leverage yang tidak menguntungkan (unfavorable) apabila perusahaan tidak menghasilkan dana sebanyak beban tetap. Tujuan utama investor melakukan investasi adalah memperoleh return yang maksimal. Semakin efisien perusahaan dalam menggunakan aktivanya maka return yang diperoleh investor akan semakin tinggi. Umumnya return merupakan salah satu alat untuk menilai besarnya keuntungan suatu saham.

Setiap keputusan investasi menyangkut dua hal yang berhubungan positif antara risiko dengan return yang diharapkan dari suatu investasi, sehingga makin besar return maka risiko yang ditanggung juga semakin besar. Return merupakan imbalan yang diperoleh dari investasi. Umumnya return memiliki dua komponen pengembalian yaitu:

1. Untung atau rugi modal (capital gain/loss), merupakan keuntungan atau kerugian investor yang diperoleh dari kelebihan Leverage jual atau Leverage beli yang keduanya terjadi di pasar sekunder.

2. Imbalan hasil, merupakan aliran kas yang diterima investor secara periodik. Imbalan yang dimaksud adalah imbalan hasil yang merupakan pendapatan. Pembagian laba perusahaan kepada pemegang saham dikenal sebagai pembagian dividen. Dividen yang diterima oleh pemegang saham tergantung pada jumlah lembar saham yang dimilikinya.
Dividen digunakan untuk mengukur kinerja saham berdasarkan dividen yang dibagikan. Semakin besar dividen maka saham tersebut semakin menarik bagi investor. Selain itu makin tinggi Leverage saham menunjukkan bahwa saham tersebut semakin diminati investor. Hal ini menunjukkan semakin tinggi Leverage saham akan menghasilkan capital gain yang besar pula. Return saham dapat dihitung dengan membandingkan antara Leverage saham periode sekarang dengan Leverage saham periode sebelumnya. Subjek penelitian yang akan dilakukan di PT. Semen Gresik di Denpasar. Menghadapi persaingan yang semakin ketat, Kualitas produksi perseroan merupakan salah satu kunci sukses yang mendorong kemajuan perusahaan. Beranjak dari hal tersebut diatas PT. Semen Gresik, secara terus menerus dipantau oleh satuan Quality Control guna menjamin kualitas produksi, agar mampu mewujudkan visi sebagai perusahaan persemenan terkemuka di asia dengan tingkat efesiensi tinggi serta mampu menunjang pembangunan daerah.

Mengingat fungsi, posisi, dan peranan PT. Semen Gresik, ditengah tengah persaingan yang begitu ketat, maka kepentingan untuk meningkatkan profit serta untuk memenuhi kewajiban jangka panjangnya menjadi begitu penting agar dikemudian hari PT. Semen Gresik, dapat mempertahankan eksistensinya serta tetap dipercaya oleh konsumen. Keberhasilan suatu usaha PT. Semen Gresik, dapat dicerminkan dari 
peranannya terhadap peningkatan nilai perusahaan serta menjamin stabilitas perseroan dalam jangka panjang. Untuk mengetahui keberhasilan PT. Semen Gresik Surticon Buana Perkasa perlu di adakannya penelitian pengaruh leverage dan profitabilitas terhadap retrun saham PT. Semen Gresik Surticon Buana perkasa. PT. Semen Gresik Surticon Buana Perkasa merupakan salah satu industry yang telah memegang peranan pentig terhadap kemajuan sejak mulai di dirikannya, sehingga secara langsung mendukung pertumbuhan perekonomian daerah.

Berdasarkan keuanagn perusahaan dapat di jelaskan bahwa leverage dan profitabilitas dalam kurun waktu 5 tahun terakhir cukup banyak mengalami peningkatan dan penurunan setiap tahunnya dalam 5 tahun terakhir mencapai angka Rp. 4.312.214.000 pada tahun 2017 pada leverage keuangan dan profitabilitas Rp. 6.565.858.000 dalam kurun waktu 5 tahun.

Mengingat pentingnya pengaruh leverage dan profitabilitas terhadap retrun saham untuk menentukan kebijakan-kebijakan guna mempertahankan kelangsungan operasional perusahaan dalam menghadapi persaingan sesama jenis usaha.

Setiap keputusan investasi menyangkut dua hal yang berhubungan positif antara risiko dengan return yang diharapkan dari suatu investasi, sehingga makin besar return maka risiko yang ditanggung juga semakin besar. Return merupakan imbalan yang diperoleh dari investasi. Umumnya return memiliki dua komponen pengembalian yaitu:

3. Untung atau rugi modal (capital gain/loss), merupakan keuntungan atau kerugian investor yang diperoleh dari kelebihan Leverage jual atau Leverage beli yang keduanya terjadi di pasar sekunder.

4. Imbalan hasil, merupakan aliran kas yang diterima investor secara periodik. Imbalan yang dimaksud adalah imbalan hasil yang merupakan pendapatan. Pembagian laba perusahaan kepada pemegang saham dikenal sebagai pembagian dividen. Dividen yang diterima oleh pemegang saham tergantung pada jumlah lembar saham yang dimilikinya.

Dividen digunakan untuk mengukur kinerja saham berdasarkan dividen yang dibagikan. Semakin besar dividen maka saham tersebut semakin menarik bagi investor. Selain itu makin tinggi Leverage saham menunjukkan bahwa saham tersebut semakin diminati investor. Hal ini menunjukkan semakin tinggi Leverage saham akan menghasilkan capital gain yang besar pula. Return saham dapat dihitung dengan membandingkan antara Leverage saham periode sekarang dengan Leverage saham periode sebelumnya. Subjek penelitian yang akan dilakukan di PT. Semen Gresik di Denpasar. Menghadapi persaingan yang semakin ketat, Kualitas produksi perseroan merupakan salah satu kunci sukses yang mendorong kemajuan perusahaan. Beranjak dari hal tersebut 
diatas PT. Semen Gresik, secara terus menerus dipantau oleh satuan Quality Control guna menjamin kualitas produksi, agar mampu mewujudkan visi sebagai perusahaan persemenan terkemuka di asia dengan tingkat efesiensi tinggi serta mampu menunjang pembangunan daerah.

\section{METODE PENELITIAN}

Berdasarkan permasalahan yang diteliti, penelitian ini digolongkan pada penelitian asosiatif, yaitu suatu penelitian yang bertujuan untuk mengetahui pengaruh sebab akibat dari variabel yang diteliti. Penelitian ini bertujuan untuk mencari tahu pengaruh dari leverage dan profitabilitas terhadap return saham pada PT. Semen Gresik Surticon Buana Perkasa Tbk. Denpasar.

Teknik analisis data dalam penelitian ini menggunakan pendekatan kuantitatif yaitu analisis statistik inferensial, terdiri dari: uji asumsi klasik yaitu uji multikolinearitas, uji normalitas dan uji heteroskedastisitas, analisis regresi linier berganda, analisis determinasi, uji signifikansi parsial (ttest) dan uji signifikansi simultan (Ftest).

\section{HASIL DAN PEMBAHASAN}

Uji Asumsi Klasik

Uji Multikolinearitas

Hasil uji multikolinearitas dapat dilihat pada Tabel 1 berikut.

Tabel 1

Hasil Uji Multikolinearitas

\begin{tabular}{|c|c|c|}
\hline \multirow{2}{*}{ Variabel Bebas } & \multicolumn{2}{|c|}{ Collinearity Statistic } \\
\hline & Tolerance & $V I F$ \\
\hline Debt to Ratio & .480 & 2.082 \\
\hline ROA & .480 & 2.082 \\
\hline
\end{tabular}

Sumber: Sumber : Olah data SPSS 25.0 for Windows, 2019.

Pada Tabel 1 dapat dilihat bahwa hasil perhitungan menunjukkan tidak ada variabel bebas yang memiliki nilai Tolerance yang kurang dari 0,10 yang berati tidak ada kolerasi antara variabel bebas yang nilainya lebih dari 95\%, nilai Variance Inflation Factor (VIF) juga menunjukkan hal yang sama, yaitu tidak ada variabel bebas yang memiliki nilai diatas 10, sehingga tidak terjadi multikolinearitas dalam model regresi.
Maka penulis mengambil penelitian dengan berdasarkan hal tersebut diatas penulis tertarik untuk mengambil judul penelitian "Pengaruh Leverage Dan Profitabilitas Terhadap Return Saham Pada PT. Semen Gresik Surticon Buana Perkasa Tbk. Denpasar". 
Uji Normalitas
Hasil uji normalitas dapat dilihat pada

Tabel 2 berikut.

Tabel 2

Hasil Uji Normalitas

\begin{tabular}{|l|c|}
\hline & Unstandardized Residual \\
\hline $\mathrm{N}$ & 5 \\
\hline Test Statistic & .146 \\
\hline Asymp. Sig. (2-tailed) & $.200^{\mathrm{c}, \mathrm{d}}$ \\
\hline
\end{tabular}

Sumber: Olah data SPSS 25.0 for Windows, 2019.

Pada Tabel 2 dapat dilihat bahwa hasil perhitungan Asymp. Sig. (2-tailed) menunjukkan nilai sebesar 0,200 lebih dibandingkan dengan 0,05 , sehingga dapat dikatakan variabel penelitian yang digunakan tersebut terdistribusi secara

normal, sehingga persamaan regresi dapat digunakan dalam penelitian.

\section{Uji Heteroskedastisitas}

Hasil uji heteroskedastisitas dapat dilihat pada Tabel 3 berikut.

Tabel 3

Hasil Uji Heteroskedastisitas

\begin{tabular}{|c|c|c|}
\hline Model & $\mathrm{t}$ & Sig. \\
\hline (Constant) & .232 & .838 \\
\hline Debt to Ratio & -.255 & .822 \\
\hline ROA & .162 & .886 \\
\hline
\end{tabular}

a. Dependent Variable: res_2

Sumber: Olah data SPSS 25.0 for Windows, 2019.

Pada Tabel 3 dapat dilihat bahwa nilai Sig. pada kedua variabel bebas menunjukkan nilai lebih besar dibandingkan dengan 0,05. Hasil ini menunjukkan bahwa koefisien regresi nilai absolut residual tidak signifikan, sehingga tidak terjadi heteroskedastisitas pada variabel leverage dan profitabilitas 0,05 .

\section{Persamaan Regresi Linier Berganda}

Hasil uji analisis regresi linier berganda dapat dilihat pada Tabel 4 berikut. 
Tabel 4

Hasil Hasil Analisis Regresi Linier Berganda

\begin{tabular}{|c|c|c|}
\hline \multirow[b]{2}{*}{ Model } & \multicolumn{2}{|c|}{ Unstandardized Coefficients } \\
\hline & B & Std. Error \\
\hline (Constant) & 132.932 & 16.568 \\
\hline Debt to Ratio & 2.841 & .519 \\
\hline$R O A$ & 6.006 & .542 \\
\hline
\end{tabular}

a. Dependent Variable: Kepuasan pengguna jasa Sumber: Olah data SPSS 25.0 for Windows, 2019.

Persamaan regresi pada Tabel 4 menjelaskan bahwa nilai $\alpha=132,932$ menunjukkan bahwa apabila nilai leverage dan profitabilitas adalah 0 , maka return saham akan bernilai $\mathrm{Rp}$ $132,932,-. \quad b_{1}=2,841$, artinya ada pengaruh yang positif antara leverage terhadap return saham pada PT. Semen Gresik Surticon Buana Perkasa Tbk Denpasar. Koefisien regresi bertanda positif berarti ada pengaruh yang searah, dimana jika leverage meningkat maka akan diikuti dengan meningkatnya return saham sebesar $\mathrm{Rp} 2,841,-$. $\mathrm{b}_{2}=$ 6,006 , artinya ada pengaruh yang positif antara profitabilitas terhadap return

saham pada PT. Semen Gresik Surticon Buana Perkasa Tbk Denpasar. Koefisien regresi bertanda positif berarti ada pengaruh yang searah, dimana jika profitabilitas meningkat maka akan diikuti dengan meningkatnya return saham sebesar Rp 6,006,- Persamaan regresi linier berganda telah lolos uji asumsi klasik, sehingga dapat digunakan untuk memprediksi perubahan $\mathrm{Y}$ yang disebabkan oleh $\mathrm{X}_{1}$ dan $\mathrm{X}_{2}$.

\section{Koefisien Determinasi (Adjusted $R$ Square)}

Hasil analisis kolerasi determinasi dapat dilihat pada Tabel 5 berikut.

Tabel 5

Hasil Kolerasi Berganda dalam Model Summary

\begin{tabular}{|l|lr|}
\hline \multicolumn{3}{|c|}{ Model Summary $^{\text {b }}$} \\
\hline Model & Adjusted R Square & 0,971 \\
\hline 1 & & \\
\hline
\end{tabular}

a. Predictors: (Constant), ROA, Debt to Ratio

b. Dependent Variable: Return Saham

Sumber: Olah data SPSS 25.0 for Windows, 2019. 
Berdasarkan Tabel 5 diketahui nilai $\mathrm{R}_{2}$ pada model summary adalah 0,971, sehingga didapat koefisien determinasi sebesar $97,1 \%$, artinya pengaruh leverage dan profitabilitas terhadap return saham adalah sebesar $97,1 \%$. Sisanya sebesar $100 \%-97,1 \%=$
2,9\% dipengaruhi oleh faktor lain yang tidak diteliti dalam penelitian ini.

\section{Uji Statistik F (F-test)}

Hasil uji hipotesis $\mathrm{F}$ dapat dilihat pada Tabel 6 berikut.

Tabel 6

Hasil Uji Statistik F pada Tabel Anova

\begin{tabular}{|r|l|r|r|}
\hline \multicolumn{2}{|c|}{ Model } & F & \multicolumn{1}{c|}{ Sig. } \\
\hline 1 & Regression & 67.940 & $.015^{\mathrm{b}}$ \\
\cline { 2 - 5 } & Residual & & \\
\cline { 2 - 4 } & Total & & \\
\hline
\end{tabular}

Berdasarkan hasil uji statistik F (Ftest) diperoleh Fhitung $=67,940$ dibandingkan dengan nilai Ftabel = 19,00 maka nilai Fhitung lebih besar dari nilai Ftabel, dan Fhitung berada pada daerah penolakan Ho. Oleh karena itu, Ho ditolak dan $\mathrm{H}_{3}$ diterima. Ini berarti bahwa pada taraf $\alpha=5 \%$ secara simultan Leverage $\left(\mathrm{X}_{1}\right)$ dan Profitabilitas $\left(\mathrm{X}_{2}\right)$ memiliki pengaruh positif dan signifikan (nyata) terhadap return saham pada PT.
Semen Gresik Surticon Buana Perkasa Tbk Denpasar (Y), sehingga hipotesis yang berbunyi "Ada pengaruh positif dan signifikan secara simultan leverage dan profitabilitas terhadap return saham pada PT. Semen Gresik surticon Buana Perkasa Tbk Denpasar" teruji kebenarannya atau Ho ditolak.

Uji Statistik t (t-test)

Hasil uji hipotesis $t$ dapat dilihat pada Tabel 7 berikut.

Tabel 7

Hasil Analisis Uji T-test

\begin{tabular}{|c|c|c|}
\hline Model & $\mathrm{t}$ & Sig. \\
\hline (Constant) & - & - \\
\hline Debt to Ratio & 5.471 & .032 \\
\hline ROA & 11.077 & .008 \\
\hline
\end{tabular}

Sumber: Olah data SPSS 25.0 for Windows, 2019. 
a. Pengaruh leverage terhadap return saham

Dari hasil uji statistik t (t-test) dapat dijelaskan bahwa, nilai t-hitung = 5,741 lebih besar dibandingkan dengan nilai $\mathrm{t}$-tabel $=2,920$ dengan nilai Sig. $=$ 0,032 kurang dari 0,05 sehingga Ho ditolak dan $\mathrm{Ha}$ diterima. Hal ini membuktikan jika Profitabilitas $\left(\mathrm{X}_{2}\right)$ dalam keadaan konstan, secara statistika pada taraf kepercayaan $(\alpha)=5 \%$, maka Leverage $\quad\left(\mathrm{X}_{1}\right) \quad$ berpengaruh signifikan/nyata terhadap return saham pada PT. Semen Gresik surticon Buana Perkasa Tbk Denpasar" teruji kebenarannya atau Ho ditolak.

b. Pengaruh profitabilitas (ROA) terhadap return saham

Dari hasil uji statistik t (t-test) dapat dijelaskan bahwa, nilai t-hitung $=$ 11,077 lebih besar dibandingkan dengan nilai t-tabel $=2,920$, dengan nilai Sig. $=0,008$ kurang dari 0,05 sehingga Ho ditolak dan $\mathrm{Ha}$ diterima. Hal ini membuktikan jika Leverage $\left(\mathrm{X}_{1}\right)$ dalam keadaan konstan, secara statistika pada taraf kepercayaan $(\alpha)=5 \%$, maka Profitabilitas $\left(\mathrm{X}_{2}\right)$ berpengaruh signifikan/nyata terhadap return saham (Y) sehingga hipotesis yang berbunyi "Profitabilitas berpengaruh positif dan signifikan terhadap return saham PT. Semen Gresik Surticon Buana Perkasa Tbk Denpasar" adalah teruji kebenarannya atau Ho ditolak.

\section{PENUTUP \\ KESIMPULAN}

Berdasarkan hasil analisis data dan pembahasan, maka dapat ditarik kesimpulan mengenai Pengaruh Leverage dan Profitabilitas Terhadap Return Saham pada PT. Semen Gresik Surticon Buana Perkasa Tbk Denpasar sebagai berikut :

a. Leverage dan profitabilitas (ROA) secara simultan berpengaruh positif dan signifikan secara simultan terhadap return saham PT. Semen Gresik Surticon Buana Perkasa Tbk Denpasar.

Leverage dan profitabilitas secara parsial berpengaruh positif dan signifikan terhadap return saham pada PT. Semen Gresik Surticon Buana Perkasa Tbk Denpasar.

\section{SARAN-SARAN}

Berdasarkan hasil kesimpulan diberikan saran sebagai berikut :

Bagi investor yang memilih berinvestasi pada saham Bank Konvensional Indonesia hendaknya dalam mengambil keputusan investasi selain mempertimbangkan rasio profitabilitas dan leverage juga perlu mempertimbangkan rasio-rasio keuangan terhadap return saham pada PT. Semen Gresik surticon Buana Perkasa Tbk Denpasar" teruji kebenarannya atau Ho ditolak.

Pengaruh profitabilitas (ROA) terhadap return saham

Dari hasil uji statistik t (t-test) dapat dijelaskan bahwa, nilai t-hitung = 11,077 lebih besar dibandingkan dengan nilai t-tabel $=2,920$, dengan nilai Sig. $=$ 0,008 kurang dari 0,05 sehingga Ho ditolak dan $\mathrm{Ha}$ diterima. Hal ini 
membuktikan jika Leverage $\left(\mathrm{X}_{1}\right)$ dalam keadaan konstan, secara statistika pada taraf kepercayaan $(\alpha)=5 \%$, maka Profitabilitas $\left(\mathrm{X}_{2}\right) \quad$ berpengaruh signifikan/nyata terhadap return saham (Y) sehingga hipotesis yang berbunyi "Profitabilitas berpengaruh positif dan signifikan terhadap return saham PT. Semen Gresik Surticon Buana Perkasa Tbk Denpasar" adalah teruji kebenarannya atau Ho ditolak.

Bagi peneliti berikutnya diharapkan menambah rasio keuangan lainnya sebagai variabel independen, karena sangat dimungkinkan rasio keuangan lain yang tidak dimasukkan dalam penelitian ini berpengaruh terhadap return saham.

\section{DAFTAR PUSTAKA}

Abdul Halim. (2005). Analisis Investasi Edisi Kedua. Salemba Empat: Jakarta.

Abdul, Alwidan Sutrisno. (2013). Analisis Pengaruh FaktorFaktor Fundamental Terhadap Leverage Saham Perusahaan Manufaktur. JurnalISBN: 978979-636-147-2. Surakarta: Universitas Islam Indonesia

Agnes Sawir. (2004). Analisis Kinerja Keuangan dan Perencanaan Keuangan Perusahaan. PT. Gramedia Pustaka Utama: Jakarta.

Alwi, Z. Iskandar. 2010. Pasar Modal Teori dan Aplikasi. Jakarta: Yayasan Pancur Siwah.
Anoraga dan Pakarti, (2006), Pengantar Pasar Modal, Rineka Cipta, Jakarta.

Anggoro,Toha (2007). Metodologi Penelitian. Jakarta : Universitas Terbuka

Arikunto, S. (2002). Prosedur penelitian suatu pendekatan praktek. Jakarta: Rineka Cipta

Arista, Desy dan Astohar. (2012). Analisis Faktor-Faktor Yang Mempengaruhi Return Saham (Kasus Pada Perusahaan Manufaktur Yang Go Public Di BEI Periode Tahun 2005-2009). Jurnal Ilmu Manajemen Dan Akuntansi Terapan Vol.3, No.1, hal 1-15.

Arilaha, Muhammad Asril. (2009). Pengaruh Free Cash Flow, Profitabilitas, Likuiditas, dan Leverage Terhadap Kebijakan Dividen. Jurnal Keuangan dan Perbankan, 13 (1) h: 78-87.

Astiyani, Lany (2018), Pengaruh Profitabilitas dan Leverage terhadap Rrturn Saham (Studi Kasus pada Bursa Efek Indonesia Tahun 20122016). Skripsi, Fakultas Ekonomi dan Bisnis Unpas

Astuti, Puji. (2006). Analisis Pengaruh Faktor-Faktor Fundamental EVA dan MVA Terhadap Return Saham. Tesis Program Pasca Sarjana. Universitas Diponegoro.

Bambang Riyanto. (2001). Dasardasar Pembelanjaan Perusahaan. BPFE, Yogyakarta. 
Brigham, Eugene. dan Houston. 2009. Fundamentals of Financial Management, 12th edition. Mason: South-Western Cengage Leaning.

Budialim, Giovani. (2013). Pengaruh Kinerja Keuangan dan Resiko Terhadap Return Saham Pada Perusahaan Sektor Customer Goods Di Bursa Efek Jakarta Periode 2007-2011. Jurnal Ekonomi Keuangan Vol.2, No.1, hal 1-23, Universitas Surabaya

Darmaji dan Fakhruddin, (2011). Pasar Modal Di Indonesia. Jakarta. Salemba Empat.

Darmaji dan Fakhruddin, (2012). Pasar Modal Di Indonesia Edisi ketiga. Jakarta. Salemba Empat.

Dedy Trisno dan Fransiska Soejono. (2008). Pengaruh Rasio Profitabilitas TerhadapHarga Saham Pada Perusahaan Pertambangan Di Bursa Efek Indonesia. Jurnal Keuangan dan Bisnis, 9(1)

Dharmastuti, Fara. (2004). Analisis Pengaruh Faktor-Faktor Keuangan Terhadap Harga Saham Perusahaan Go Pulbik di BEJ. Jurnal Manajeman Vol 1 No.1. Jakarta Fakultas Ekonomi Universitas Atmajaya.

Dwikirana dan prasetiono. (2016). Analisis Pengaruh Rasio Profitabilitas, Likuiditas dan Leverage Terhadap Return Saham Dengan Nilai Perusahaan Sebagai variable Intervening. Jurnal Ekonomi dan Bisnis Vol,5, No,3, hal 1-15, Universitas Diponegoro
Dwi Prastowo. (2011). Analisis Laporan Keuangan. Edisi Ketiga. YKPN: Jakarta.

(2014). Analisis Laporan Keuangan. Unit Penerbit dan Percetakan Sekolah Tinggi Ilmu Manajemen YKPN. ISBN : 978979-3532-99-8

Fahmi, Irham dan Yovi Lavianti Hadi. 2009. Teori Portofolio dan Analisis Investasi Teori dan Soal Jawab, Cetakan kedua. Bandung: Alfabeta

Fahmi. (2009). Teori Portofolio dan Analisis Investasi. Alfabeta: Bandung. Irham

(2013). Analisis Laporan Keuangan, Cetakan Ke-3. Alfabeta: Bandung.

Ghozali, Imam, (2018), Aplikasi Analisis Multivariate dengan Program IBM SPSS 25, Semarang: Badan Penerbit Universitas Diponegoro.

Hartono, (2010). Teori Portofolio dan analisis investasi. Yogyakarta: BPFE UGM

Harahap, Sofyan Syafri. (2004). Teori Akuntansi. Raja Grafindo Persada: Jakarta. (2010). Teori Akuntansi. Raja Grafindo Persada: Jakarta. . (2011). Teori Akuntansi Edisi Revisi. Raja Grafindo Persada: Jakarta.

Hasibuan, Malayu. (2014). Manajemen Sumber Daya Manusia. Jakarta: Bumi. Aksara 
Hastuti dan Sudibyo, (1998). Pengaruh Publikasi Laporan Arus Kas Terhadap Volume Perdagangan Saham Perusahaan Di Bursa Efek Jakarta. jurnal riset akuntansi Indonesia. vol.1 No 2 (juli): 239-254.

Irawati, (2006). Manajemen Keuangan. Cetakan Kesatu. Bandung: PT Pusaka

Jogiyanto, (2000). Teori Portofolio dan Analisis Investasi, Edisi Kedua, Cetakan Pertama, Yogyakarta: BPFE. . (2007). Teori Portofolio dan Analisis Investasi (Edisi keempat) Yogyakarta: BPFE. . (2010). Teori Portofolio dan Analisis Investasi (Edisi ketujuh) Yogyakarta: BPFE . (2013). Teori Portofolio dan Analisis Investasi. Edisi Kedepalan. BPFE: Yogyakarta

Kasmir, (2010) Bank dan Lembaga Keuangan

Lainnya.jakarta:rajawali pers.

. (2012) Bank dan Lembaga Keuangan

Lainnya.jakarta:rajawali pers.

- (2013) Bank dan Lembaga Keuangan

Lainnya.jakarta:rajawali pers.

Kieso, Donald E.,Jerry J. Weygandt, Terry D. Warfield. (2011). Intermedite Accounting, Volume 1. IFRS Edition. United States of America : Quad/Graphic, Inc.

Machfiro, Sonia dan Eko Ganis Sukoharsono. (2011). The Effect of Financial Variables on the Company's Value (Study on Food and Beverage Companies that are listed on Indonesia Stock Exchange Period 20082011).

Mamduh M. Hanafi. (2009). Analisis Laporan Keuangan. Edisi Keempat. YKPN. Yogyakarta.

Mariani, Yudiaatmaja dan Yulianthini. (2016). Pengharuh Profitabilitas dan Leverage Terhadap Return Saham. Jurnal Ekonomi Keuangan Vol,4, Universitas Pendidikan Ganesha

Munawir, (1998). Analisis Laporan Keuangan. Edisi 4.yogyakarta: liberty . (2010). Analisa Laporan Keuangan, Edisi 4. Liberty: Yogyakarta. Pernyataan Standar Akuntansi Keuangan (PSAK). Penyajian Laporan Keuangan.

Ngaisah, Siti. (2008). Pengaruh Rasio Profitablitas dan Leverage Terhadap Return Saham Pada Perusahaan Yang Terdaftar Di Jakarta Islamic Index tahun 2004-2006. Skripsi. Universitas islam negeri sunan kalijaga. eJournal Bisma Universitas Pendidikan Ganesha Jurusan Manajemen (Volume 4 Tahun 2016)

Pramana dan Pangestuti. (2016). Pengaruh Rasio Profitabilitas, Leverage, Size dan Sales Growth Terhadap Return Saham Yang Dimediasi Oleh Dividen. Jurnal Ekonomi dan 
Bisnis Vol.5, No,3, hal 1-15, Universitas Diponegoro

Rangkuti, (2008), The Power Of Brands, Jakarta : Penerbit Gramedia

Reeves, James M, Carl S. Wareen. (2009). Pengantar AkuntansiAdaptasi Indonesia Buku 1. Diterjemahkan oleh Damayanti Dian. Salemba Empat: Jakarta. 108 Robert Ang. (2010). Buku Pintar Pasar Modal Edisi ketujuh. Media Soft Indonesia: Jakarta.

Riduwan dan Akdon, (2013). Rumus dan Data dalam Analisis Statistika. Penerbit Alfabeta, Bandung.

Sartono Agus, 2001. Manajemen Keuangan ( Teori dan Aplikasi ), BPFE,Yogyakarta.

Sartono. Agus, (2010). Manajemen Keuangan: Teori dan Aplikasi. Edisi Keenpat. Yogyakarta: BPFE.

Saud, Husnan (2001) Dasar-dasar Teori Portofolio dan Analisis Sekuritas. Edisi kelima. Yogyakarta: BPFE . (2005). Dasar-dasar Teori Portofolio dan Analisis Sekuritas. UPP STIM YKPN: Yogyakarta.

Sugiyono, (2017). Metode Penelitian Kuantitatif Kualitatif, Bandung: CV Alfabeta. (2017), Metode Penelitian Bisnis, Bandung: Alfabeda
Suhairy, (2006). Pengaruh Rasio Profitabilitas Dan Leverage Terhadap Return Saham Perusahaan Manufaktur Di BEJ. Tesis. Universitas Sumatatera Utara

Sunarto, (2001). Pengaruh Rasio Profitabilitas dan Leverage Terhadap Return Saham Perusahaan Manufaktur di BEJ. Tesis. Jurnal bisnis dan ekonomi

Sunariyah, (2003), Pengantar Pengetahuan Pasar Modal, Edisi Kelima, Yogyakarta: Penerbit UPP STIM YKPN.

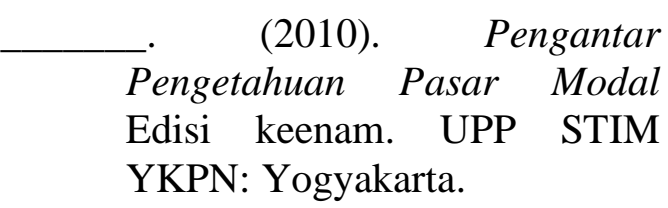

Sutrisno, (2013) Manajemen Keuangan Teori, Konsep dan Aplikasi. Yogyakarta Ekonisia UII

Sulaiman, Handi, dan Ana. (2008). Pengaruh kinerja Keuangan terhadap Return Saham Pada Perusahaan Manufaktur di BEJ. Jurnal Penelitian dan Pengembangan Akuntansi Vol: 2 No.2 Juli 2008.

Syahbani, Murni dan Fredy SN (2017). Analisis Pengaruh Rasio Likuiditas, Leverage dan profitabilitas Terhadap Return Saham Pada Perusahaan Makanan dan Minuman. Jurnal Pendidikan Ekonomi Vol.7, No.1 , hal 1-6, Universitas Pancasila.

Ulupin, (2007). Analisis Pengaruh Rasio Likuiditas , Leverage, 
Aktivitas dan Profitabilitas Terhadap Return Saham. (Studi

Pada Perusahaan Makanan dan Minuman Dengan Katagori Industri Barang Konsumsi Di $B E J)$. Jurnal. Fakultas Ekonomi. Universitas Udayana.

Weston J.Fred. dan Eugene F. Brigham, (2001), Dasar-Dasar manajemen Keuangan, Erlangga: Jakarta. 